\title{
CONTESTS AMONG BUREAUCRATS
}

\author{
DIETER BÖS
}

\author{
CESIFo Working PAPER No. 807 \\ CATEgory 1: Public FinANCE \\ NOVEMBER 2002
}
An electronic version of the paper may be downloaded
- from the SSRN website: www.SSRN.com
- from the CESifo website: www.CESifo.de




\title{
CONTESTS AMONG BUREAUCRATS
}

\begin{abstract}
This paper deals with double lobbying: several bureaucrats participate in joint lobbying to get a high total departmental budget, but they also engage in antagonistic lobbying to reap as high a share of the total budget as possible. The antagonistic lobbying constitutes a contest among the bureaucrats. This paper characterizes the Nash equilibria in lobbying and shows in which way exogenously fixed bureaucratic incomes induce the same or different lobbying behavior as incentive incomes.
\end{abstract}

JEL Classification: D72, D73, D74.

Keywords: bureaucracy, lobbying, contests.

\author{
Dieter Bös \\ Department of Economics \\ University of Bonn \\ Adenauerallee 24-42 \\ 53113 Bonn \\ Germany \\ dieter.boes@uni-bonn.de
}




\section{Introduction}

The trade-off between joint interests and antagonistic interests is a general phenomenon which can often be observed in political economics. It is particularly relevant whenever a group of economic agents unites their efforts in order to receive a large amount of money for the total group, but also splits their efforts because every individual agent wants to get a high personal share of the total money. In this paper we consider various bureaucrats who are part of a department. They share a total departmental budget which is appropriated by a sponsor, be it the parliament or a minister. Every single bureaucrat wants to administrate an individual budget that is as high as possible. A high individual budget results if a bureaucrat gets a high share of a high departmental budget. Therefore, all bureaucrats together participate in joint lobbying to get a high departmental budget. However, every bureaucrat will also engage in antagonistic lobbying against his co-bureaucrats in order to induce the sponsor to appropriate a high individual budget to his personal bureau. Antagonistic lobbying constitutes a contest among bureaucrats.

There are many examples which can be used to illustrate the interplay between joint and antagonistic lobbying in economic practice. Consider the usual process of budgeting. National defense, for instance, is awarded a total sum of money by the parliament. All generals unite in joint lobbying to attain a high defense budget. But, of course, the army, the navy, and the air force will engage in antagonistic lobbying to increase their individual sub-budgets. Alternatively, think of a group of scientific researchers who apply for a total grant which is split among the various professors. The interest in a high total budget will induce joint lobbying efforts, the interest in a high personal share in this budget will induce antagonistic lobbying. Finally, consider problems of fiscal federalism, where states get fiscal grants from the federal government. All states will unite in joint lobbying to reap a high share of all taxpayers' money for the group of the states. However, at the same time, antagonistic lobbying takes place, because every state will want to increase its share at the expense of the other states.

To capture the essentials of the particular trade-off between joint and antagonistic lobbying we set up a contest model which on the one hand builds on the tradition of rent-seeking models, but on the other hand exhibits special features which have not yet been addressed in the literature on lobbying.

(i) The bureaucrats do not engage in a winner-take-it-all contest, they compete for a share of a divisible budget and not for the whole of an indivisible budget. This is in contrast to much of the literature on rent-seeking contests as, for instance, Tullock 
(1980, 1984), Hillman and Katz (1984), Hillman and Samet (1987) and Ursprung (1990).

(ii) The bureaucrat's lobbying efforts influence both their share in the budget and the total budget. This feature, in itself, is not new. In Chung (1996), Hausken (1995a,b, 2000), and Van Long and Vousden (1987: section II) each individual's lobbying effort benefits the agents by increasing the share of the prize they get (a private good) and by increasing the total prize to be allocated to the agents (a public good). So the core of these models is a twofold positive effect of the individual lobbying efforts. However, while there are many cases where this assumption is meaningful (see the examples in Chung, 1996: 56-57), the above specification does not cope with the special cases mentioned in the beginning of the introduction to this paper. These special cases cannot be characterized by the interplay of two positive effects of individual lobbying. Rather, we have a positive and a negative effect: the amount of effort spent to reap a larger share of the budget is lost for the joint effort which is needed to increase the budget itself. This idea is similar in spirit to Skaperdas and Grofman (1995) who investigate voting contests where the political candidates have one unit of time or resource that they can allocate between positive campaigning (which attracts undecided voters) and negative campaigning (which reduces the number of undecided voters a competitor would have attracted in the absence of negative campaigning). ${ }^{1}$

(iii) We do not model a rent-seeking contest where the contestants spend money to gain a prize or part of a price. In contrast, in our model the agents spend time to influence the sponsor. The total time endowment for lobbying is exogenously given and normalized to unity and it is divided by any individual bureaucrat into time spent for antagonistic lobbying and time spent for joint lobbying. This is in strong contrast to most of the usual lobbying models which deal with campaign contributions and the like, that is, with monetary expenditures whose total amount is not exogenously given - on the contrary, its endogenous determination is the basis of rent dissipation and the literature then asks the question of how far various institutional settings influence the extent of rent dissipation. The present paper has nothing to do with rent dissipation, it is directed at totally different questions, in particular, at the incentive effects that various income schedules exert on the lobbying efforts of public-sector employees and civil servants.

(iv) We distinguish various types of bureaucratic incomes:

- exogenously fixed incomes,

- incentive incomes which alternatively depend on the total departmental budget or 
on the individual sub-budget which is administrated by the bureaucrat in question. It will be shown that incentive incomes do not necessarily lead to lobbying strategies which differ from those chosen in the case of fixed incomes.

The paper is organized as follows. Section 2 presents the model, defining how joint lobbying determines the total departmental budget und how antagonistic lobbying characterizes the contest among the bureaucrats. The model extends Skaperdas's (1992) approach by the explicit inclusion of bureaucratic income schedules and by explicit constraints on the individual budgets the bureaucrats have to administrate. In Section 3 we present the Nash equilibrium in lobbying efforts. We deal with existence and uniqueness and give an overview of the various possible types of lobbying equilibria. Section 4 is devoted to the characterization of several interesting types of equilibria, namely full cooperation (no antagonistic lobbying), polarization (one agent fully concentrates on antagonistic lobbying, the other fully concentrates on joint lobbying), and split lobbying (interior solutions for both lobbying efforts of both agents). Finally, in Section 5 we show that any bureaucrat spends as much money as possible for pure waste, regardless of whether he is paid a fixed income or any sort of incentive income. A brief conclusion follows. There are several appendices which will be sent to the reader on request.

\section{The model}

We consider a department which consists of two bureaucrats. The sponsor, for example the minister or the parliament, appropriates a departmental budget to finance a particular project which is jointly produced by both bureaucrats. However, the bureaucrats do not draw personal satisfaction from the total departmental budget, but only from the individual budgets they have to administrate, which are some shares of the total departmental budget. Therefore, the bureaucrats engage in double lobbying: they lobby jointly to get a high departmental budget, and they lobby antagonistically to get a high individual share in this total budget. We assume that the bureaucrats spend $x_{i}, i=1,2$ time units for joint lobbying and $y_{i}$ time units for antagonistic lobbying, where $x_{i}+y_{i}=1$. The assumption of an exogenously fixed time endowment for lobbying may seem to be restrictive. However, the qualitative results of the paper remain unchanged if the total time spent for lobbying is endogenized. This is shown in Appendix A.4.

The effects of the various types of lobbying are captured by the following Assumptions 1 and 2. Lobbying is private information, and cannot be verified 
before a court.

Assumption 1 (joint lobbying): The total departmental budget $B\left(x_{1}, x_{2}\right)$ is a function of the joint-lobbying efforts $x_{1}$ and $x_{2}$. The budget-formation function is twice continuously differentiable. It exhibits positive but non-increasing marginal products, $B_{1}>0, B_{2}>0, B_{11} \leq 0$ and $B_{22} \leq 0 .^{2}$ The cross derivative $B_{12}$ can be zero, positive, or negative. $B(0,0)=0, B(1,1)=\bar{B}$.

The budget-formation function $B\left(x_{1}, x_{2}\right)$ can be interpreted in the same way as a standard production function that abstracts from the exact technological and organizational details of the production process. How effective an agent is in his joint lobbying is measured by his marginal product $B_{i}$. The budget is bounded both from above and from below. First, $B(1,1)=\bar{B}$ is the maximum budget which can be achieved by joint lobbying, so there is no danger that an infinite budget might arise, even in the special case where the budget-formation function exhibits constant returns to scale. ${ }^{3}$ Second, $B(0,0)=0$ is the minimum budget: joint lobbying is a necessary condition for any budget, since the sponsor would not even know of the project unless he learned of it by the lobbying of the bureaucrats. The normalization to zero has been made for convenience. The analysis would become more complicated without further economic insight if we assumed that $B(0,0)=B^{\text {min }}$, with $B^{\text {min }}$ as a minimum budget which the sponsor in any case would appropriate for the realization of the project at stake. Note that the combination of the assumptions $B(0,0)=0$ and $B_{i}>0, i=1,2$ implies that $B\left(0, x_{2}\right)>0$ and $B\left(x_{1}, 0\right)>0$. This excludes budgetformation functions where a budget is only appropriated if both bureaucrats engage in joint lobbying. ${ }^{4}$ Therefore, situations in which one bureaucrat fully specializes in antagonistic lobbying may be equilibria of the game with a non-zero departmental budget.

Let us next turn to the individual budgets of the two bureaucrats. The bureaucrats engage in a lobbying contest to try to get as high a share of the departmental budget as possible. The antagonistic-lobbying efforts $y_{i}$ determine the splitting of the departmental budget: the more time an agent devotes to antagonistic lobbying, the higher his individual share.

Assumption 2 (antagonistic lobbying): $\quad p$ is the share of the budget that is finally administrated by bureaucrat 1 , a share $(1-p)$ is administrated by bureaucrat 2. These shares depend on the antagonistic-lobbying efforts $y_{1}$ and $y_{2}$. The contest-success function $p\left(y_{1}, y_{2}\right)$ is twice continuously differentiable and has the following properties: 
- $p\left(y_{1}, y_{2}\right) \in[0,1] \quad \forall y_{1}, y_{2} \in[0,1] \quad$ (share of the budget),

- $p_{1}>0, p_{2}<0, p_{11}<0, p_{22}>0^{5} \quad$ (antagonistic lobbying $y_{i}$ has positive but

- $p\left(y_{1}, y_{2}\right)=1-p\left(y_{2}, y_{1}\right) \quad$ (anonymity of agents).

Note that the anonymity of agents implies that equal lobbying induces equal budgets, $p(y, y)=1 / 2$. Assumption 2 defines a contest-success function. How effective an agent is in his antagonistic lobbying is measured by $p_{i}$, his marginal success in increasing his share of the departmental budget. As an example of a contest-success function the reader may refer to Tullock's (1980) ratio model $p=y_{1} /\left(y_{1}+y_{2}\right)$, which exhibits decreasing marginal effectiveness of antagonistic-lobbying efforts. Assumption 2 of this paper can be fulfilled by the Tullock ratio model, except for $y_{1}=y_{2}=0 .{ }^{6}$ On the other hand, Assumption 2 is not fulfilled by Hirshleifer's (1989) logistic contest-success function $p=1 /\left(1+\exp \left(k\left(y_{2}-y_{1}\right)\right)\right.$, which implies convexity of $p$ if $y_{1}<y_{2}$ and concavity thereafter. ${ }^{7}$

The bureaucrats are paid an income for their activities. Details on the various possible income schedules are presented in Assumption 3.

Assumption 3 (income schedules): Denote by $I$ the income of bureaucrat 1 and by $J$ the income of bureaucrat 2 . There are three alternative income schedules: ${ }^{8}$

- fixed incomes: $I=\bar{I}, J=\bar{J}, \quad \bar{I}=\bar{J}=0$ if $B=0$;

- incentive incomes depending on the total budget:

$$
\begin{aligned}
& I=I(B), \quad I^{\prime}>0, I^{\prime \prime}<0, I(0)=0, \\
& J=J(B), \quad J^{\prime}>0, J^{\prime \prime}<0, J(0)=0,
\end{aligned}
$$

- incentive incomes depending on the individual budgets:

$$
\begin{aligned}
& I=I(p B), \quad I^{\prime}>0, I^{\prime \prime}<0, I(0)=0, \\
& J=J((1-p) B), \quad J^{\prime}>0, J^{\prime \prime}<0, J(0)=0 .
\end{aligned}
$$

Note that the sponsor can only observe the total departmental budget and the individual budgets and, therefore, the bureaucratic incomes can only be conditioned on these budgetary values. The sponsor could not condition incomes on lobbying efforts which are unobservable. The sponsor also does not know that $x_{i}+y_{i}=1$, otherwise he could calculate the lobbying efforts on the basis of his observation of the total and of the individual budgets. For the results of this paper we do not need an explicit model for the determination of the bureaucratic incomes. This renders our results fairly general. In particular, the incentive incomes can be any type of non-linear concave functions. 
We allow that circumstances from outside the model influence the bureaucratic incomes. By way of example, the duration of individual employment may be relevant for the payment, or special bonus schemes may be awarded to restrain a bureaucrat from accepting an outside job. Therefore, we have assumed that the agents may earn different fixed incomes $\bar{I}, \bar{J}$ or different incentive incomes $I(\cdot), J(\cdot)$. Of course, our specifications include the special cases of equal incomes $\bar{I}=\bar{J}$, or $I(B)=J(B) \forall B$. Similarly, if incentive incomes are conditioned on the individual budgets, the income schedules may well be identical, $I(b)=J(b)=f(b) \forall b$, where $b$ is the individual budget. In this case the agents get equal incomes if their individual budgets are the same, for instance, because both apply the same strategies, $y_{1}=y_{2}$, whence $p=1 / 2$.

The bureaucrats are egoistic individuals. They want to earn a high income, but they also get satisfaction from the administration of a high individual budget. Therefore, their individual utilities consist of a weighted average of their individual budgets and of their personal incomes, where the weights are given by $\theta_{i} \in(0,1), i=1,2$.

$$
\begin{aligned}
& U_{1}=\theta_{1} p B+\left(1-\theta_{1}\right) I \\
& U_{2}=\theta_{2}(1-p) B+\left(1-\theta_{2}\right) J
\end{aligned}
$$

There are several particularities of these specifications which should briefly be mentioned. First, the linearity of utility has merely been chosen for convenience. All propositions of the paper are also valid if the more general utility functions $U_{1}(p B, I)$ and $U_{2}((1-p) B, J)$ are considered. ${ }^{9}$ Second, we have intentionally excluded the case of $\theta_{i}=0$. In this case there would be no incentive to antagonistic lobbying if the incomes depend on the total budget. Third, it would not be meaningful to deduct disutility from lobbying as further argument in the bureaucrats' utility functions. Since the total amount of lobbying is exogenously given $\left(x_{i}+y_{i}=1\right)$, and the bureaucrats only split total lobbying into two sub-lobbying activities, their disutility from lobbying is always the same. If such a constant disutility were introduced into the utility functions, it would not change any marginal condition.

The bureaucrats face the following budget constraints. First, there is the total departmental budget appropriated by the sponsor,

$$
B \geq I+J+2 \bar{K}
$$

where $I, J$ correspond to any of the three income schedules treated in the paper and $2 \bar{K}$ are exogenously given capital investments which are necessary for the completion of the project. The budget constraint is written as an inequality to allow for 
bureaucratic waste: if the total budget $B$ is strictly greater than the agents' incomes and the capital investments, the excess money is used for pure waste, for instance for unnecessary buildings, marble staircases in these buildings, large cars, hiring of further unproductive employees and the like. If the project is not performed, we trivially assume that $\bar{K}=0$ and that there is no waste. Only the bureaucrats know the technology which determines $2 \bar{K}$, only they can tell apart money that is spent for capital investments and money that is spent for waste. The sponsor only observes what he pays, that is, $B, I$ and $J$. Therefore, the budget constraint is "soft:" if the bureaucrats succeed in inducing the sponsor to appropriate a budget in excess of $I, J$ plus $2 \bar{K}$, they can use the excess money for pure waste.

The sponsor splits the total budget into two individual budgets which are as soft

as the total budget. For convenience we assume that for his individual productive activities each bureaucrat needs capital investments of $\bar{K}$. Then, the two individual budget constraints can be written as follows:

$$
p B \geq I+\bar{K} ; \quad(1-p) B \geq J+\bar{K}
$$

If a bureaucrat did not comply with his budget constraint, he would be fired or, alternatively, be subject to an extremely unpleasant monitoring by the sponsor and the media. Hence, when dividing his effort between joint and antagonistic lobbying, any bureaucrat explicitly takes account of his individual budget constraint.

\section{Equilibrium}

\subsection{Feasibility of the project}

Our model is characterized by many exogenous constants, for instance the capital investments $\bar{K}$ and, in the case of fixed incomes, $\bar{I}, \bar{J}$. Moreover, there are many functions whose shape is exogenously given, such as $B(\cdot)$, or the income schedules $I(\cdot), J(\cdot)$. Therefore, one could well think of situations where even extremely high joint lobbying would not attain a departmental budget that is high enough to finance the project: consider, for instance, a situation where $\bar{B}:=B(1,1)=500$ mill. Euro, whereas the project requires capital investments of $2 \bar{K}=2$ billion Euro. In this case the bureaucrats will forget about this project and neither engage in joint lobbying nor in antagonistic lobbying.

Therefore, before playing the lobbying game, the agents check the feasibility of the project. ${ }^{10}$ For this purpose hypothetical lobbying efforts are calculated by the 
agents, taking as given the efforts of the other agent. We always choose antagonistic lobbying $y_{i}$ as instrument variables. Therefore, the bureaucrats consider utilities $U_{i}\left(y_{1}, y_{2}\right)$, contest success $p\left(y_{1}, y_{2}\right)$ and a departmental budget $B\left(1-y_{1}, 1-y_{2}\right) .{ }^{11}$ Any agent's maximization has to take into account the boundaries of $y_{i} \in[0,1]$. Therefore, the agents apply the following optimization approach:

$$
\begin{array}{ll}
\max _{y_{1} \in[0,1]} & \theta_{1} p B+\left(1-\theta_{1}\right) I, \\
\max _{y_{2} \in[0,1]} & \theta_{2}(1-p) B+\left(1-\theta_{2}\right) J .
\end{array}
$$

The bureaucrats' calculations lead to Nash values $\hat{x}_{i}, \hat{y}_{i}, i=1,2 .{ }^{12}$ The project is considered not to be feasible if

$$
p\left(\hat{y}_{1}, \hat{y}_{2}\right) B\left(\hat{x}_{1}, \hat{x}_{2}\right)<I+\bar{K}
$$

and/or

$$
\left(1-p\left(\hat{y}_{1}, \hat{y}_{2}\right)\right) B\left(\hat{x}_{1}, \hat{x}_{2}\right)<J+\bar{K}
$$

where $I$ and $J$ refer to all kinds of income schedules as defined in Assumption 3. Note that the bureaucrats ignore the individual budget constraints in their hypothetical optimization (5) and (6). Therefore they attain hypothetical effort levels which may fulfill or not fulfill these individual constraints. If at least one constraint is not fulfilled, the project is considered not to be feasible. In this case, the bureaucrats exert neither joint nor antagonistic lobbying, the incomes and the capital investments are equal to zero.

The chosen feasibility criterion, conditions (7) and (8) is the most plausible one for the following reasons. Both players know that they await harsh punishment if they violate the individual budget constraints. First, violation may imply dismissal, and this is not only feared by the dismissed bureaucrat but also by his fellow because it takes time to find replacement and it takes time to set up the necessary relationship with a new colleague (which type of budget-formation function $B(\cdot)$ will hold with a newcomer, is unknown to the bureaucrat who is not fired). Second, if violation does not imply direct dismissal, but being exposed to strong criticism by the superiors and by the media, this also throws bad light on the other bureaucrat and, therefore, he prefers not to follow up a project where his fellow bureaucrat cannot fulfill his individual budget constraint.

\subsection{Determination of the equilibrium}

Let us now assume the project has passed the test of feasibility. This implies that both bureaucrats know that their individual budget constraints will not be violated 
if the project if performed. Therefore, it is not necessary to explicitly consider these constraints in the bureaucrats' lobbying game: each agent decides how to split his lobbying in order to maximize his utility, taking as given the lobbying activities of the other agent. This is the same optimization as shown in (5) and (6) above. The Lagrangean functions of the agents' optimization approaches are as follows:

$$
\begin{array}{r}
\theta_{1} p B+\left(1-\theta_{1}\right) I+\lambda_{11}\left(1-y_{1}\right)+\lambda_{12} y_{1} \\
\theta_{2}(1-p) B+\left(1-\theta_{2}\right) J+\lambda_{21}\left(1-y_{2}\right)+\lambda_{22} y_{2}
\end{array}
$$

where $\lambda_{i j}$ are the Lagrangean parameters. The first-order conditions are different according to the type of income schedule. For agent 1, we obtain

$$
\begin{aligned}
I=\bar{I}: & {\left[p_{1} B-p B_{1}\right] \theta_{1}-\lambda_{11}+\lambda_{12}=0, } \\
I=I(B): & {\left[p_{1} B-p B_{1}\right] \theta_{1}-\left(1-\theta_{1}\right) I^{\prime} B_{1}-\lambda_{11}+\lambda_{12}=0, } \\
I=I(p B): & {\left[p_{1} B-p B_{1}\right]\left\{\theta_{1}+\left(1-\theta_{1}\right) I^{\prime}\right\}-\lambda_{11}+\lambda_{12}=0, } \\
\forall I: & \lambda_{11}\left(1-y_{1}\right)=0, \quad \lambda_{12} y_{1}=0, \quad \lambda_{11}, \lambda_{12} \geq 0 .
\end{aligned}
$$

Analogous first-order conditions hold for agent $2 .{ }^{13}$

The bureaucrats' first-order conditions determine reaction functions $y_{1}\left(y_{2}\right), y_{2}\left(y_{1}\right)$. A Nash equilibrium $y_{1}^{N}, y_{2}^{N}$ of the game is a fixed point $y_{1}^{N}=y_{1}\left(y_{2}\left(y_{1}^{N}\right)\right) \wedge y_{2}^{N}=y_{2}\left(y_{1}\left(y_{2}^{N}\right)\right)$.

Proposition 1: (i) There exists a Nash equilibrium $y_{1}^{N}, y_{2}^{N}$ of the game. (ii) Under a fairly complicated special assumption (which differs according to the income schedule) this equilibrium is unique.

Proof: presented in Appendix A.1 which will be sent to the reader upon request.

\subsection{Equilibrium strategies and income schemes}

It can be shown that fixed incomes induce the same behavior as incentive incomes that depend on the agents' individual budgets. This is a challenging result since a priori one would have expected that the explicit stipulation of an incentive income should decisively change the behavior of the bureaucrats.

Proposition 2: The Nash-equilibrium strategies $y_{i}^{N}$ are identical for fixed incomes and for incomes that depend on the individual budgets.

Proof: Compare the first-order conditions (11) and (13). The term $\left[p_{1} B-p B_{1}\right]$ is equal in both conditions. In (11) this term is multiplied by $\theta_{1}>0$, in (13) by 
$\theta_{1}+\left(1-\theta_{1}\right) I^{\prime}>0$. An analogous interpretation holds for the marginal conditions of the second bureaucrat.

Now consider interior solutions $y_{i} \in[0,1]$, whence $\lambda_{i j}=0, i=1,2$. Then the following system of two equations in the two unknown variables $y_{1}, y_{2}$ determines the strategies both in the case of fixed incomes and of incomes that depend on the individual budgets: (a) $p_{1} B-p B_{1}=0$, and (b) $-p_{2} B-(1-p) B_{2}=0$. Since we have proved the uniqueness of the Nash equilibria, the strategies must therefore be identical in both cases. The extension to corner solutions is straightforward.

Proposition 2 has the following intuitive explanation. Consider bureaucrat 1 (the story for bureaucrat 2 is analogous). If this agent earns a fixed income, he has lobbying incentives that result from his interest in a high individual budget, that is, from the term $\theta_{1} p B$ in his utility function. If his income depends on the individual budget, he has exactly the same lobbying incentives. First, he is directly interested in his individual budget, $\theta_{1} p B$, and second, he is interested in his personal income which also is a function of his individual budget, $\left(1-\theta_{1}\right) I(p B)$. Therefore, this income schedule does not change the lobbying strategies as compared with a fixed income. This is different if the incentive income depends on the total budget. Then agent 1 is directly interested in the individual budget, $\theta_{1} p B$, whereas the income gives another lobbying incentive, namely in favor of joint lobbying, $\left(1-\theta_{1}\right) I(B)$.

On the other hand, while Proposition 2 is plausible, it is definitely surprising. After all, a fixed income implies a utility function which is linear in the individual budget, whereas an incentive income, that depends on the individual budget, implies a utility function that is concave in the individual budget. Hence, the reader might have expected differences in the lobbying activities which would be similar to the differences in rent-seeking strategies of risk-neutral and risk-averse agents. We know from Konrad and Schlesinger (1997) that the risk-averse agent tends to spend less for rent-seeking because he fears the risk, but at the same time tends to spend more because this increases the likelihood of success; which effect dominates, depends on the specifications of the relevant functions and parameters. Note, however, that our model differs decisively from the type of rent-seeking model applied in Konrad and Schlesinger. First, in our model there is no risk. Neither $\theta_{i}$ nor $p$ are probabilities. Second, the question of more or less expenditures for lobbying is a non-question in our model since the total investment in lobbying is always unity; it is only the split-up of the lobbying activities which matters. Third, the concavity of $I$ and $J$ is set by the sponsor and not by the bureaucrats. 


\subsection{Types of equilibria}

Let us distinguish the following three types of equilibria: ${ }^{14}$

- 'Full conflict' refers to an equilibrium where $y_{1}^{N}=y_{2}^{N}=1$, that is, there is no joint lobbying, but only antagonistic lobbying.

- 'Full cooperation' refers to an equilibrium where $y_{1}^{N}=y_{2}^{N}=0$, that is, the bureaucrats spend all their time for joint lobbying, there is no antagonism.

- 'Partial cooperation' comprises all other equilibria, for instance: ${ }^{15}$

- both bureaucrats split their efforts between joint and antagonistic lobbying,

- one bureaucrat devotes all his effort to joint lobbying, whereas the other splits his effort,

- one bureaucrat devotes all his effort to antagonistic lobbying, whereas the other splits his effort,

- one bureaucrat devotes all his effort to joint lobbying, the other devotes all his effort to antagonistic lobbying.

After presenting this typology, we immediately recognize that a full-conflict equilibrium is precluded in our model.

Proposition 3: Full conflict $\left(y_{1}^{N}=y_{2}^{N}=1\right)$ can never be an equilibrium.

Proof: $y_{1}^{N}=y_{2}^{N}=1$ implies $x_{1}^{N}=x_{2}^{N}=0, B(0,0)=0$. This implies utilities $U_{1}(0,0)=U_{2}(0,0)=0$. Any joint lobbying activity will increase the utility of at least one agent.

\section{Characterization of the equilibria}

\subsection{Rewriting the first-order conditions}

For the following characterization of the various types of equilibria we will rewrite the first-order conditions (11) to (13). For this purpose let us assume that the budgetformation function $B$ exhibits constant returns to scale. This implies $B\left(x_{1}, x_{2}\right)=$ $x_{1} B_{1}\left(x_{1}, x_{2}\right)+x_{2} B_{2}\left(x_{1}, x_{2}\right)$. Therefore, the first-order conditions of the bureaucrats' optimization approach can be written as

$$
p_{1} x_{1} B_{1}+p_{1} x_{2} B_{2}-\mathcal{L}_{1} B_{1} \gtreqless 0
$$




$$
-p_{2} x_{1} B_{1}-p_{2} x_{2} B_{2}-\mathcal{L}_{2} B_{2} \gtreqless 0,
$$

where all functions are evaluated at the relevant equilibrium strategies $\left(y_{1}^{N}, y_{2}^{N}\right)$. The rewritten first-order conditions reveal the most important consequences of the assumption of constant returns to scale: it does not matter how effective the bureaucrats are in their joint lobbying. What really matters is the ratio $B_{1} / B_{2}$ : is agent 1 more effective in joint lobbying than agent 2 ?

The differences in income schedules are captured by the variables $\mathcal{L}_{i}$. They are identical for fixed incomes and for incomes that depend on the individual budgets,

$$
\mathcal{L}_{1}=p ; \quad \mathcal{L}_{2}=1-p
$$

In contrast, if the incomes depend on the total budget, we obtain

$$
\mathcal{L}_{1}=p+\frac{1-\theta_{1}}{\theta_{1}} I^{\prime}(B) ; \quad \mathcal{L}_{2}=1-p+\frac{1-\theta_{2}}{\theta_{2}} \quad J^{\prime}(B) .
$$

To get more insight into the rewritten first-order conditions, consider the following two extreme scenarios. First, for the sake of the argument, assume that antagonistic lobbying is fully ineffective, $\left|p_{i}\right|=0$. We ignore for the moment that this contradicts Assumption 2. It can easily be seen that in this case there is no incentive to antagonistic lobbying whatsoever. We substitute into (15) and (16) and obtain ${ }^{16}$

$$
-\mathcal{L}_{1} B_{1}<0 \Rightarrow y_{1}=0 ; \quad-\mathcal{L}_{2} B_{2}<0 \Rightarrow y_{2}=0
$$

Second, consider the scenarios where $p_{1}=\mathcal{L}_{1} / x_{1}^{N}$ or $-p_{2}=\mathcal{L}_{2} / x_{2}^{N}$. Then antagonistic lobbying is highly effective: a bureaucrat who faces so large a $\left|p_{i}\right|$ will devote all of his time to fight his colleague. ${ }^{17}$ We substitute into (15) and (16) and get

$$
p_{1} x_{2} B_{2}>0 \Rightarrow y_{1}^{N}=1 ; \quad-p_{2} x_{1} B_{1}>0 \Rightarrow y_{2}^{N}=1 \text {. }
$$

The two extreme scenarios illustrate that it will be the straightforward way to characterize the various types of equilibria by the particular boundaries of the effectiveness of antagonistic lobbying.

\subsection{Full cooperation}

Full cooperation is given if the bureaucrats do not exert any antagonistic lobbying, $y_{1}^{N}=y_{2}^{N}=0$. In this case the agents face the following conditions

$$
\begin{aligned}
p_{1} x_{1} B_{1}+p_{1} x_{2} B_{2}-\mathcal{L}_{1} B_{1} & \leq 0 \\
-p_{2} x_{1} B_{1}-p_{2} x_{2} B_{2}-\mathcal{L}_{2} B_{2} & \leq 0
\end{aligned}
$$


We substitute the particular properties of the full-cooperation case, that is, $x_{1}^{N}=$ $x_{2}^{N}=1$, and $p_{1}(0,0)=-p_{2}(0,0) .{ }^{18}$ Then we combine the conditions for agent 1 and agent 2 and obtain

$$
\frac{\mathcal{L}_{2}-p_{1}}{p_{1}} \geq \frac{B_{1}}{B_{2}} \geq \frac{p_{1}}{\mathcal{L}_{1}-p_{1}}
$$

It can easily be shown that these two inequalities can only hold if

$$
p_{1} \leq \frac{\mathcal{L}_{1} \mathcal{L}_{2}}{\mathcal{L}_{1}+\mathcal{L}_{2}}
$$

Since in the full-cooperation case $p_{1}=-p_{2}$, the same upper limit holds for the second bureaucrat. This upper limit is particularly simple for fixed incomes and for incomes that depend on the individual budgets. Recall that Assumption 2 requires $p(0,0)=1 / 2$. Therefore, we have $\mathcal{L}_{1}=\mathcal{L}_{2}=1 / 2$ which implies

$$
p_{1} \leq 1 / 4 ; \quad-p_{2} \leq 1 / 4
$$

Proposition 4: (i) Full cooperation can occur as an equilibrium of the game if antagonistic lobbying is sufficiently ineffective.

(ii) If antagonistic lobbying is extremely ineffective $\left(p_{1} \rightarrow 0\right)$, then full cooperation will occur regardless of how effective the agents are in their joint lobbying.

(iii) If antagonistic lobbying is low but relatively effective $\left(p_{1} \rightarrow \mathcal{L}_{1} \mathcal{L}_{2} /\left(\mathcal{L}_{1}+\mathcal{L}_{2}\right)\right)$, full coordination requires equal efficiency in joint lobbying $\left(B_{1}=B_{2}\right)$ if the agents earn fixed incomes or incomes that depend on the individual budgets.

Proof: (i) follows directly from (24) and also from (25).

(ii) Substitute $p_{1} \rightarrow 0$ into the conditions (23). Then, (23) converges to $\infty \geq B_{1} / B_{2} \geq 0$.

(iii) Substitute $p_{1}=\mathcal{L}_{1} \mathcal{L}_{2} /\left(\mathcal{L}_{1}+\mathcal{L}_{2}\right)$ into the conditions (23). The result is $\mathcal{L}_{2} / \mathcal{L}_{1} \geq B_{1} / B_{2} \geq \mathcal{L}_{2} / \mathcal{L}_{1}$ which can only hold if $B_{1} / B_{2}=\mathcal{L}_{2} / \mathcal{L}_{1}$. For fixed incomes and incomes that depend on the individual budgets, we have $\mathcal{L}_{1}=\mathcal{L}_{2}=1 / 2$ and, therefore $B_{1}=B_{2}$.

Proposition 4(i) is fairly straightforward: it is kind of trivial that full cooperation occurs if antagonistic lobbying is sufficiently ineffective. More interesting are the statements of Proposition 4(ii) and 4(iii) which refer to the interplay between antagonistic and joint lobbying. If the agents are fully ineffective in antagonistic lobbying, it only matters that there is some effectiveness in joint lobbying. ${ }^{19}$ However, if the agents become more effective in antagonistic lobbying, full cooperation will only occur if they are similarly effective in joint lobbying, at least if they earn 
fixed incomes or incomes that depend on the individual budgets. This result is due to the constant-returns-to-scale assumption which yields a maximum budget if both agents are equally effective. If the incentive incomes depend on the total budget, this result is changed because the different income schedules $\left(I^{\prime}(B) \neq J^{\prime}(B)\right)$ give diverging incentives. Therefore, in this case relatively effective antagonistic lobbyists will in the full-cooperation equilibrium adjust to an inverse-effectiveness condition $B_{1} / B_{2}=\mathcal{L}_{2} / \mathcal{L}_{1}$.

\subsection{Partial cooperation}

It would be tedious to present a detailed analysis of all the various types of partial cooperation. We rather restrict the discussion to the cases of polarization and split lobbying. We first consider polarization where bureaucrat 1 engages only in joint lobbying, $y_{1}^{N}=0$, whereas bureaucrat 2 engages only in antagonistic lobbying, $y_{2}^{N}=1$. The agents face the following conditions

$$
\begin{aligned}
p_{1} x_{1} B_{1}+p_{1} x_{2} B_{2}-\mathcal{L}_{1} B_{1} & \leq 0 \\
-p_{2} x_{1} B_{1}-p_{2} x_{2} B_{2}-\mathcal{L}_{2} B_{2} & \geq 0
\end{aligned}
$$

Substituting the particular properties of the polarization case, that is, $x_{1}^{N}=1$ and $x_{2}^{N}=0$, we obtain

$$
\begin{aligned}
p_{1} & \leq \mathcal{L}_{1} \\
-p_{2} & \geq \mathcal{L}_{2} \frac{B_{2}}{B_{1}}
\end{aligned}
$$

These conditions should be compared with the case of full cooperation, where the agents are relatively ineffective in their antagonistic lobbying. In contrast, in the polarization case the aggressive bureaucrat 2 is quite successful in the fight against the other player and less effective in the joint fight for the departmental budget. Bureaucrat 1, on the other hand, recognizes that antagonistic lobbying promises low success, although $p_{1}$ may well be higher than in the case of full cooperation. Consequently, bureaucrat 2 fully specializes in the hostile strategy, while bureaucrat 1 fully specializes in joint lobbying. We obtain the following proposition.

Proposition 5: Polarization with $y_{1}^{N}=0$ and $y_{2}^{N}=1$ can occur as an equilibrium of the game if the hostile agent is effective in antagonistic lobbying but less effective in joint lobbying. It is the other way round for the friendly agent.

Proof: follows directly from (28) and (29). 
Next we analyse the case of split lobbying, where both agents engage in both types of lobbying, $y_{1}^{N}, y_{2}^{N} \in(0,1)$. The agents face the following first-order conditions

$$
\begin{aligned}
p_{1} x_{1} B_{1}+p_{1} x_{2} B_{2}-\mathcal{L}_{1} B_{1} & =0 \\
-p_{2} x_{1} B_{1}-p_{2} x_{2} B_{2}-\mathcal{L}_{2} B_{2} & =0
\end{aligned}
$$

which can be rewritten as

$$
\begin{aligned}
p_{1} & =\frac{\mathcal{L}_{1}}{x_{1}+x_{2} B_{2} / B_{1}}<\frac{\mathcal{L}_{1}}{x_{1}}, \\
-p_{2} & =\frac{\mathcal{L}_{2}}{x_{2}+x_{1} B_{1} / B_{2}}<\frac{\mathcal{L}_{2}}{x_{2}} .
\end{aligned}
$$

To evaluate this result recall the extreme scenarios mentioned in subsection 4.1, where $p_{1}=\mathcal{L}_{1} / x_{1}^{N}$ or $-p_{2}=\mathcal{L}_{2} / x_{2}^{N}$ were shown to induce full antagonistic lobbying. The conditions (32) and (33) show that in a split-lobbying equilibrium the values of $p_{1}$ and $-p_{2}$ are significantly below these upper limits. On the other hand, $p_{1}$ and $-p_{2}$ must be larger than in the case of full cooperation. Therefore, we have the following proposition:

Proposition 6: A split-lobbying equilibrium requires medium efficiency in antagonistic lobbying, where "medium efficiency" means

$$
\left.\frac{\mathcal{L}_{1}}{x_{1}}\right|_{y_{1}^{N}=y_{2}^{N}=1}>p_{1}>\left.\frac{\mathcal{L}_{1} \mathcal{L}_{2}}{\mathcal{L}_{1}+\mathcal{L}_{2}}\right|_{y_{1}^{N}=y_{2}^{N}=0} .
$$

Proof: follows directly from (32) and (33), and a comparison with (24).

Any more detailed interpretation of the equalities in (32) and (33) is tricky, since both sides of the equalities are determined by the strategies $y_{1}^{N}$ and $y_{2}^{N}$. However, a particular connection between antagonistic and joint lobbying can be found by dividing the equalities in (32) and in (33). This yields

$$
\frac{p_{1}}{-p_{2}}=\frac{\mathcal{L}_{1}}{\mathcal{L}_{2}} \cdot \frac{B_{1}}{B_{2}}
$$

Accordingly, split lobbying requires a proportionality between the relative efficiency of antagonistic and joint lobbying, the proportionality factor being $\mathcal{L}_{1} / \mathcal{L}_{2}$. This factor is equal to unity if the agents' incomes are fixed or depend on the individual budgets, and if these agents spend the same amount of effort for antagonistic lobbying $\left(y_{1}^{N}=y_{2}^{N} \Rightarrow p=1 / 2 \Rightarrow \mathcal{L}_{1}=\mathcal{L}_{2}\right)$. 
To provide a better intuitive feeling of what goes on in a split-lobbying case, let us calculate a simple example for fixed incomes and incentive incomes that depend on the individual budgets $\left(\mathcal{L}_{1}=p, \mathcal{L}_{2}=1-p\right)$. We choose a constantreturns-to-scale technology $B=a x_{1}+x_{2}$, where the first agent is more effective in joint lobbying, $a>1$. The contest-success function is specified according to Tullock (1980), $p=y_{1} /\left(y_{1}+y_{2}\right)$. Then we have $p_{1}=y_{2} /\left(y_{1}+y_{2}\right)^{2}$ and $-p_{2}=y_{1} /\left(y_{1}+y_{2}\right)^{2}$. Split lobbying requires

$$
\begin{aligned}
p_{1} & =\mathcal{L}_{1} B_{1} / B, \\
-p_{2} & =\mathcal{L}_{2} B_{2} / B .
\end{aligned}
$$

Substituting for $p_{i}, \mathcal{L}_{i}, B_{i}$ and $B$, we obtain the following system of equations:

$$
\begin{aligned}
a y_{1}^{2}+y_{2}^{2}+2 a y_{1} y_{2}-(1+a) y_{2} & =0 \\
a y_{1}^{2}+y_{2}^{2}+2 y_{1} y_{2}-(1+a) y_{1} & =0
\end{aligned}
$$

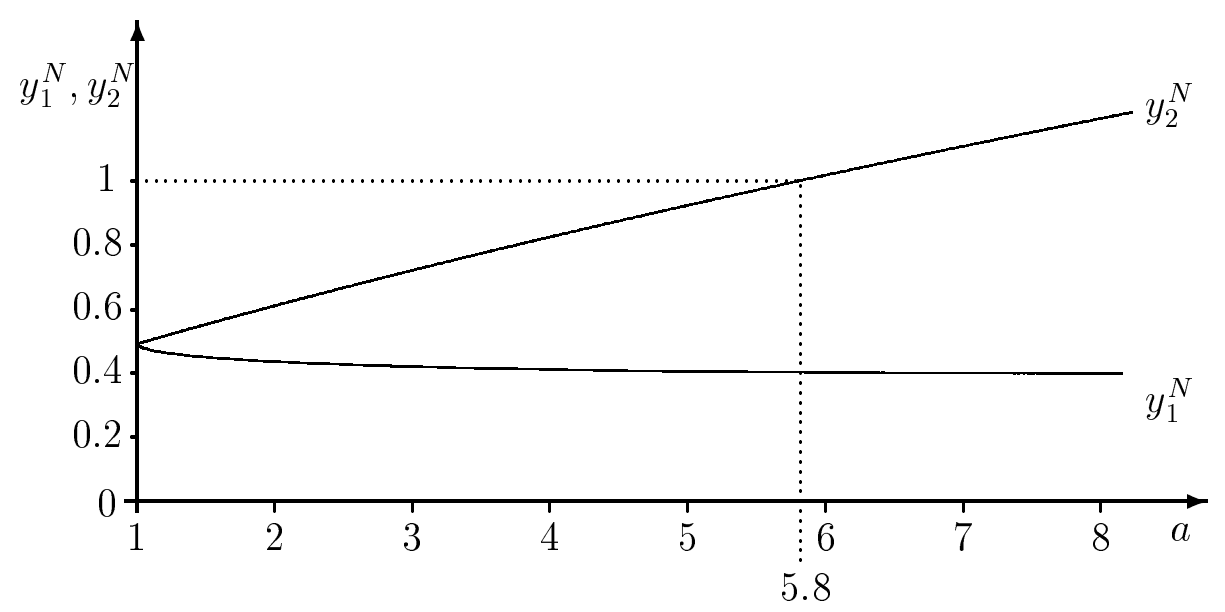

Figure 1: Antagonistic strategies (example)

Figure 1 presents the antagonistic-lobbying strategies which result from the example. ${ }^{20}$ If $a=1$, both agents split their activity evenly between antagonistic and joint lobbying $\left(y_{1}^{N}=y_{2}^{N}=0.5\right)$. For $a>1$, both agents concentrate on that type of lobbying in which they have a relative advantage: agent 1 devotes more than 50 per cent of his time for joint lobbying, agent 2 spends more than 50 per cent of his time for antagonistic lobbying. Increasing $a$ implies a sharp increase in agent 2's hostility, while it only leads to a weak increase of agent 1's joint lobbying. Too pronounced differences in the effectiveness of joint lobbying make split lobbying impossible: if $a$ exceeds $3+2 \sqrt{2} \simeq 5,828$, agent 2 will fully engage in antagonistic lobbying, choosing $y_{2}^{N}=1$ and, therefore, leave the split-cooperation case. 


\section{Remarks on the extent of pure waste}

Until now we have investigated the choice of the bureaucrats' lobbying investments: after checking the feasibility of the project, the agents maximize their objective functions with respect to the antagonistic lobbying efforts $y_{1}$ and $y_{2}$. The feasibility check guarantees that the individual budget constraints are never violated. They may be binding or non-binding at the agents' Nash equilibrium. This implies four possible cases as shown in figure $1 .^{21}$

\begin{tabular}{|r|r|}
\hline$p B=I+\bar{K}$ & $p B>I+\bar{K}$ \\
$(1-p)=J+\bar{K}$ & $(1-p) B=J+\bar{K}$ \\
\hline$p B=I+\bar{K}$ & $p B>I+\bar{K}$ \\
$(1-p) B>J+\bar{K}$ & $(1-p) B>J+\bar{K}$ \\
\hline
\end{tabular}

Table 1: Individual budget constraints at the Nash equilibrium

These four cases differ with respect to the extent of pure waste. Whether any individual budget constraint is binding or not, depends on the agents' choice of lobbying and on the exogenous framework: the exogenously given functions $p, B$ and $I$, and the exogenously given constant $\bar{K}$. Therefore, any of the four cases of Table 1 can occur, depending on the particular constellation of the framework of the model.

Let us rewrite the individual budget constraints by explicitly introducing pure waste as slack variables $W_{1}, W_{2}$ :

$$
\begin{aligned}
p B & =I+\bar{K}+W_{1}, \\
(1-p) B & =J+\bar{K}+W_{2} .
\end{aligned}
$$

The pure-waste variables measure the degree of slack in the individual budget constraints. For the following we concentrate on agent 1 . The extension to agent 2 is straightforward.

The slack variable $W_{1}$ is zero if the particular constellation of the exogenous framework implies that at the agents' Nash equilibrium we have $p B=I+\bar{K}$. This constellation makes it impossible for the agent to devote money to waste. However, the framework may also allow for $p B>I+\bar{K}$, in which case pure waste occurs. The agent is always interested in fully exhausting the possibility of waste, since his utility is monotonically increasing in waste, as can easily be seen by substituting (39) into the agent's objective function:

$$
\theta_{1} p B+\left(1-\theta_{1}\right) I \equiv \theta_{1}\left(I+\bar{K}+W_{1}\right)+\left(1-\theta_{1}\right) I
$$


The Niskanen type of bureaucrat has no incentive whatsoever to return money to the sponsor; whenever it is possible he will use the money for waste. And this behavior is always the same regardless of the chosen income schedule: the incentive incomes do not reduce waste. We can formulate the following Proposition 7.

Proposition 7: If at the agents' Nash equilibrium the exogenous framework offers the possibility of pure waste, $p B>I+\bar{K}$, then this possibility will always fully be exhausted by the bureaucrat. This holds for a fixed income as well as for an incentive income regardless of whether it depends on the individual budget or on the total departmental budget.

Proof: trivial.

\section{Conclusion}

This paper deals with the trade-off between joint lobbying and antagonistic lobbying. Joint lobbying determines the total budget that is awarded to a group of bureaucrats, whereas antagonistic lobbying characterizes the contest among the bureaucrats who fight each other to get a high share in the total budget. Each bureaucrat has to consider a budget constraint, that is, his budget must be sufficiently high to cover his personal income and his share of the investment costs. If a budget constraint is not binding, the remaining money is used for pure waste. We have obtained the following results:

- Fixed incomes induce the same behavior as incentive incomes that depend on the agents' individual budgets. Incentive incomes that depend on the total departmental budget give an incentive to increased joint lobbying.

- Full cooperation can occur as an equilibrium if antagonistic lobbying is sufficiently ineffective. "Split lobbying" requires medium efficiency in antagonistic lobbying. "Polarization," where one bureaucrat abstains from antagonistic lobbying whereas the other bureaucrat abstains from joint lobbying, is a Nash equilibrium if the hostile agent is effective in antagonistic lobbying but less effective in joint lobbying. It is the other way round for the friendly agent.

- The bureaucrats will always fully exhaust any possibility to spend money for pure waste. This holds for all the various types of incomes treated in this paper: incentive incomes do not reduce waste.

Recently, in most European countries there have been debates about the introduction of incentive payments for civil servants and employees in the public 
sector. Starting from models of private firms the efficiency-improving consequenes of incentive incomes have been taken for granted and, accordingly, the incentive schedules often have been seen as a panacea against public-sector inefficiencies. Counterarguments in the public discussion typically refer to the multidimensionality of the tasks performed by civil servants or employees in the public sector. A good example is the recent German debate about the introduction of incentive salaries for university professors. The present paper challenges the belief in the superiority of incentive payments in the public sector even for the case of one-dimensional tasks. It is shown that bureaucrats whose income depends on their individual budgets behave exactly in the same way as bureaucrats who are paid a fixed income.

\section{Acknowledgements}

I gratefully acknowledge helpful comments by G. DeFraja, York, T. Gaube, Bonn, G. Gyárfás, Bonn, M. Kolmar, Konstanz, Kai Konrad, Berlin, S. Nitzan, Ramat-Gan and G. Tillmann, Mainz.

\section{Notes}

${ }^{1}$ There are various other papers whose models differ decisively from ours, but that also distinguish between efforts that increase the prize for the group and efforts which increase the individual share in this prize. See, for instance, Glazer's (2002) distinction between external and internal rent seeking and Inderst et al.'s (2002) distinction between inter-divisional and intradivisional contests in hierarchical firms. In Konrad (2000) the agents choose rent-seeking efforts which increase the probability to gain a prize and sabotage efforts which reduce the probability that other contestants get the prize.

${ }^{2}$ The subscripts denote partial derivatives.

${ }^{3}$ This assumption will be made in section 4 below, but only in this very section.

${ }^{4}$ Functions of this type produce particular problems with respect to the uniqueness of equilibria. See, for instance, Skaperdas (1992: 724).

${ }^{5}$ We do not impose any restrictions on the cross derivative $p_{12}$. 
${ }^{6}$ An interesting contest-success function is presented in Nitzan (1991a: 1524) and in Nitzan (1991b: 44). In these papers a proportion $a$ of the rent is distributed on egalitarian grounds and the rest is distributed according to relative effort. In our paper this would imply a specification $p=a \cdot 1 / 2+(1-a) \cdot y_{1} /\left(y_{1}+y_{2}\right)$. In the same way as Tullock's ratio model, Nitzan's function is not well-defined if $y_{1}=y_{2}=0$.

${ }^{7}$ Hirshleifer's function is, for example, applied in Skaperdas (1992). In our model it is not guaranteed, and in fact it is impossible for a large class of problems, to guarantee the existence of interior equilibria in the case of the Hirshleifer function, whereas the Tullock function leads to robust interior solutions. Compare Körber and Kolmar (1996).

${ }^{8}$ A straightforward extension of our model would refer to income schedules which combine the three alternatives mentioned in Assumption 3, for instance, $I=\beta_{1} \bar{I}_{1}+$ $\beta_{2} I_{2}(B)+\beta_{3} I_{3}(p B)$.

${ }^{9}$ With positive first derivatives and weakly negative second derivatives.

${ }^{10}$ Such a first stage on the decision of whether to enter the game or not can implicitly be found in Katz et al. (1990), Nitzan (1991), Davis and Reilly (1999) they all restrict the analysis to interior solutions of lobbying, thus excluding the case where the agents decide not to lobby at all. An explicit modelling of such a two-stage setting can be found in Wärneryd (1998) and Müller and Wärneryd (2001).

${ }^{11}$ If no misunderstanding is possible, we will drop all functional dependencies of the various functions, that is to say, $p=p\left(y_{1}, y_{2}\right), B=B\left(1-y_{1}, 1-y_{2}\right)$, etc.

${ }^{12}$ For existence and uniqueness of this Nash equilibrium see Appendix A.1 which will be sent to the reader on request.

${ }^{13}$ Replace $p_{1}$ with $-p_{2}, p$ with $(1-p), I^{\prime}$ with $J^{\prime}$ and all subscripts ' 1 ' with subscripts ' 2 .'

${ }^{14}$ Note that the terminology of this paper differs from Skaperdas (1992). The definition of full cooperation is the same, but partial cooperation in his paper only refers to Pareto-efficient outcomes of the game. We do not impose this restriction, hence, our definition is much wider. On the other hand, our definition of full conflict is much narrower than his definition of conflict. 
${ }^{15}$ Details are given in appendix A.2.

${ }^{16}$ Note that $p_{1}=0$ implies $y_{1}^{N}=0$, but that $y_{1}^{N}=0$ may also occur for $p_{1}>0$. An analogous warning holds for the equations (20).

${ }^{17}$ The case where both agents face so large a $\left|p_{i}\right|$ was excluded in Proposition 3.

${ }^{18}$ This property follows from the anonymity of agents, see Assumption 2. Differentiate the equation $p\left(y_{1}, y_{2}\right)=1-p\left(y_{2}, y_{1}\right)$ with respect to $y_{1}$ to get $p_{1}\left(y_{1}, y_{2}\right)=$ $-p_{2}\left(y_{2}, y_{1}\right)$ and evaluate at the equilibrium $y_{1}^{N}, y_{2}^{N}=(0,0)$.

${ }^{19}$ This is wrong in Skaperdas (1992) who accentuates this requirement of (nearly) identical opportunity costs for all cases of full-cooperation equilibria.

${ }^{20}$ Details of the solution of this system of equations are presented in Appendix A.3.

${ }^{21}$ If both constraints are binding, the constraints could directly be used to determine $y_{1}$ and $y_{2}$, as shown in an example in the Appendix.

\section{References}

Bös, D. and Kolmar, M. (2000). Anarchy, efficiency, and redistribution. CESifo Research Memorandum No. 357. Forthcoming in Journal of Public Economics.

Chung, T.-Y. (1996). Rent-seeking contest when the prize increases with aggregate efforts. Public Choice 87(1-2): 55-66.

Davis, D. D. and Reilly, R. J. (1999). Rent-seeking with non-identical sharing rules: an equilibrium rescued. Public Choice 100(1-2): 31-38.

Glazer, A. (2002). Allies as rivals: internal and external rent seeking. Journal of Economic Behavior \& Organization 48(2), 155-162.

Hausken, K. (1995a). Intra-level and Inter-level interaction. Rationality and Society 7(4): 465-488.

Hausken, K. (1995b). The dynamics of within-group and between-group interaction. Journal of Mathematical Economics 24(7): 655-687.

Hausken, K. (2000). Cooperation and between-group competition. Journal of Economic Behavior \& Organization 42(3) 417-425.

Hillman, A. L. and Katz, E. (1984). Risk-averse rent seekers and the social cost of monopoly power. Economic Journal 94(March): 104-110.

Hillman, A. L. and Samet, D. (1987). Dissipation of contestable rents by small numbers of contenders. Public Choice 54(1): 63-82. 
Hirshleifer, J. (1989). Conflict and rent-seeking success functions: ratio vs. difference models of relative success. Public Choice 63(2): 101-112.

Inderst, R., Müller, H. M. and Wärneryd, K. (2002). Distributional conflict in organisations. CEPR Discussion Paper.

Katz, E., Nitzan, S. and Rosenberg, J. (1990). Rent-seeking for pure public goods. Public Choice 65(1): 49-60.

Konrad, K. A. (2000). Sabotage in rent-seeking contests. Journal of Law, Economics \& Organization 16(1): 155-165.

Konrad, K. A. and Schlesinger, H. (1997). Risk aversion in rent-seeking and rent-augmenting games. Economic Journal 107(November): 1671-1683.

Körber, A. and Kolmar, M. (1996). To fight or not to fight? An analysis of submission, struggle, and the design of contests. Public Choice 88(3-4): 381-392.

Müller, H.M., and Wärneryd, K. (2001): Inside versus outside ownership: A political theory of the firm, Rand Journal of Economics 32 (3): 527-541.

Nitzan, S: (1991a). Collective rent dissipation. Economic Journal 101(November): 1522-1534.

Nitzan, S. (1991b). Rent-seeking with non-identical sharing rules. Public Choice 71(1-2): 43-50.

Skaperdas, S, (1992). Cooperation, conflict, and power in the absence of property rights. American Economic Review 82(4): 720-739.

Skaperdas, S. and Grofman, B. (1995). Modeling negative campaigning. American Political Science Review 89(1): 49-61.

Tullock, G. (1980). Efficient rent-seeking. In: J. M. Buchanan, R. D. Tollison and G. Tullock (Eds.), Toward a theory of the rent-seeking society., 97-112. College Station: Texas A \& M University Press.

Tullock, G. (1984). Long-run equilibrium and total expenditures in rent-seeking: A comment. Public Choice 43(1): 95-97.

Ursprung, H. W. (1990). Public goods, rent dissipation, and candidate competition. Economics and Politics 2(2): 115-142.

Van Long, N. and Vousden, N. (1987). Risk-averse rent seeking with shared rents. Economic Journal 97(December): 971-985.

Wärneryd, K. (1998): Distributional conflict and jurisdictional organization. Journal of Public Economics 69 (3): 435-450. 


\section{Appendix (not for publication)}

\section{A.1 Proof of Proposition $1^{22}$}

(i) Existence of the Nash equilibrium of stage 2 of the game: ${ }^{23}$

The second-order conditions of $U_{1}, U_{2}$ with respect to $y_{1}, y_{2}$ are always fulfilled. For agent 1 the partial derivatives $\partial^{2} U_{1} / \partial y_{1}^{2}$ are as follows:

$$
\begin{aligned}
I=\bar{I}: & {\left[p_{11} B-2 p_{1} B_{1}+p B_{11}\right] \theta_{1}<0, } \\
I=I(B): & {\left[p_{11} B-2 p_{1} B_{1}+p B_{11}\right] \theta_{1}+\left(1-\theta_{1}\right)\left[I^{\prime \prime} B_{1}^{2}+I^{\prime} B_{11}\right]<0, } \\
I=I(p B): & {\left[p_{11} B-2 p_{1} B_{1}+p B_{11}\right]\left\{\theta_{1}+(1-\theta) I^{\prime}\right\}+\left(p_{1} B-p B_{1}\right)^{2}\left(1-\theta_{1}\right) I^{\prime \prime}<0 . }
\end{aligned}
$$

Analogous second-order conditions prevail for agent 2. The strict inequalities follow from Assumptions 1,2 and 3.

Both individuals' optimization problems are strictly convex, which implies that a maximizer exists and is unique. This guarantees the existence of reaction functions $y_{1}\left(y_{2}\right):[0,1] \times[0,1] \rightarrow[0,1], y_{2}\left(y_{1}\right):[0,1] \times[0,1] \rightarrow[0,1]$. Furthermore, $p, p_{1}, p_{2}, B, B_{1}, B_{2}, B_{11}, B_{22}$ are all continuous, which implies that the reaction functions are continuous as well. The existence of an equilibrium is therefore a direct consequence of Brouwer's fixed-point theorem.

\section{(ii) Uniqueness of the bureaucrats' Nash equilibrium. ${ }^{24}$}

In any equilibrium of stage 2 of the game we can either have $y_{i}^{N} \in(0,1)$ or $y_{i}^{N}=\{0,1\}$. In the latter case, it can either be characterized by $\partial U_{i} / \partial y_{i}=0$ or $\partial U_{i} / \partial y_{i} \neq 0$. Equilibria in which the inequality condition is fulfilled for at least one individual will be called boundary equilibria, whereas all other equilibria will be called interior equilibria.

Lemma A.1: If there exists no equilibrium that is locally unstable, then the equilibrium $y_{1}^{N}, y_{2}^{N}$ is unique.

Proof: See Skaperdas (1992), proof of Theorem 2.

Hence, it suffices to rule out local instability of equilibria.

Lemma A.2: Every boundary equilibrium $y_{1}^{N}, y_{2}^{N}$ is locally stable.

Proof: A boundary equilibrium is characterized by $\partial U_{i} / \partial y_{i}<0$ if $y_{i}=0$ or by $\partial U_{i} / \partial y_{i}>0$ if $y_{i}=1$. In both cases there is no incentive to deviate from the corner solution. 
Lemma A.3: An interior equilibrium $y_{1}^{N}, y_{2}^{N}$ is locally stable if and only if $d y_{1}\left(y_{2}\right) / d y_{2} \cdot d y_{2}\left(y_{1}\right) / d y_{1}<1$ at the equilibrium. This holds under a fairly complicated special assumption (which differs according to the income schedule).

The derivative of the reaction function of agent $i$ with respect to a change in $y_{j}$ can be derived by totally differentiating the first-order condition of agent $i$ with respect to $y_{i}$ and $y_{j}$ (remember that we are in an interior equilibrium, hence $\left.\partial U_{i} / \partial y_{i}=0\right)$. This yields

$$
\frac{\partial y_{i}\left(y_{j}\right)}{\partial y_{j}}=-\frac{\frac{\partial^{2} U_{i}}{\partial y_{i} \partial y_{j}}}{\frac{\partial^{2} U_{i}}{\partial y_{i}^{2}}}, \quad i, j=1,2, i \neq j
$$

Hence, local stability requires that

$$
\frac{\frac{\partial^{2} U_{1}}{\partial y_{1} \partial y_{2}}}{\frac{\partial^{2} U_{1}}{\partial y_{1}^{2}}} \frac{\partial^{2} U_{2}}{\frac{\partial y_{2} \partial y_{1}}{\partial y_{2}^{2}}}<1
$$

Consider the case of fixed incomes, $I=\bar{I}, J=\bar{J}$. Then the second derivatives in (A.2) are $\partial^{2} U_{1} / \partial y_{1}^{2}=\theta_{1}\left(p_{11} B-2 p_{1} B_{1}+p B_{11}\right), \partial^{2} U_{1} /\left(\partial y_{1} \partial y_{2}\right)=$ $\theta_{1}\left(p_{12} B-p_{1} B_{2}-p_{2} B_{1}+p B_{12}\right), \partial^{2} U_{2} / \partial y_{2}^{2}=\theta_{2}\left(-p_{22} B+2 p_{2} B_{2}+(1-p) B_{22}\right)$, and $\partial^{2} U_{2} /\left(\partial y_{2} \partial y_{1}\right)=\theta_{2}\left(-p_{12} F+p_{1} F_{2}+p_{2} F_{1}+(1-p) F_{12}\right)$. Substituting in (A.2) yields the condition for local stability. For incentive incomes the various terms become more complicated, but the procedure is identical.

Lemmas 1 to 3 imply Proposition 1(ii).

\section{(iii) Uniqueness in a special case.}

If a departmental budget $B$ is achieved by joint lobbying and this budget is binding, there may be a continuum of $\left\{x_{1}, x_{2}\right\}$-values which lead to the same budget. Consider, for instance, the following case:

$$
B\left(x_{1}, x_{2}\right)=x_{1}+x_{2},
$$

where

$$
B=\bar{I}+\bar{J}+2 \bar{K}=1
$$

However, this continuum of solutions - a problem which is well-known from many public-good analyses - does not imply that there is a continuum of solutions in 
stage 2 of our game. The binding departmental budget constraints requires binding individual constraints,

$$
\begin{aligned}
p B & =\bar{I}+\bar{K} \\
(1-p) B & =\bar{J}+\bar{K}
\end{aligned}
$$

Given Assumption 2, ${ }^{25}$ this system of equation implies a unique solution $\left\{x_{1}^{N}, x_{2}^{N}, y_{1}^{N}, y_{2}^{N}\right\}$ in spite of the continuum of solutions for equation (A.3). Consider, for instance the following case where $p\left(y_{1}, y_{2}\right)$ is defined according to Tullock (1980), that is,

$$
p\left(y_{1}, y_{2}\right)=\frac{y_{1}}{y_{1}+y_{2}}
$$

Let us require, say,

$$
p B=0.4 ; \quad(1-p) B=0.6
$$

Solving this system of equations for $y_{1}$ and $y_{2}$ yields the unique values of $y_{1}=0.4$ and $y_{2}=0.6$.

\section{A.2 Types of equilibria}

Table A.1 presents the precise characterization of the various Nash equilibria which may result from the one-shot game. ${ }^{26}$ All functions are evaluated at the values given in columns $y_{1}^{N}, y_{2}^{N}$. 


\begin{tabular}{ccccc}
\hline eq. strategies & \multicolumn{2}{c}{ FOC } & condition for existence \\
$y_{1}^{N}$ & $y_{2}^{N}$ & ind. 1 & ind. 2 & \\
\hline
\end{tabular}

\section{full cooperation:}

$0 \quad 0 \quad U_{1}^{1} \leq 0 \quad U_{2}^{2} \leq 0 \quad \frac{\mathcal{L}-p_{1}}{p_{1}} \geq \frac{B_{1}}{B_{2}} \geq \frac{p_{1}}{\mathcal{L}-p_{1}}$.

partial cooperation:

\begin{tabular}{|c|c|c|c|c|c|}
\hline split lobbying: & $(0,1)$ & $(0,1)$ & $U_{1}^{1}=0$ & $U_{2}^{2}=0$ & $\begin{array}{l}\frac{x_{2} p_{1}}{\mathcal{L}_{1}-p_{1} x_{1}}=\frac{B_{1}}{B_{2}}=\frac{\mathcal{L}_{2}+p_{2} x}{-p_{2} x_{1}} \\
\wedge \quad \mathcal{L}_{1}>p_{1} x_{1}, \mathcal{L}_{2}>-p_{2} x_{2}\end{array}$ \\
\hline coop. subm.1: & 0 & $(0,1)$ & $U_{1}^{1} \leq 0$ & $U_{2}^{2}=0$ & $\begin{array}{l}\frac{x_{2} p_{1}}{\mathcal{L}_{1}-p_{1}} \leq \frac{B_{1}}{B_{2}}=\frac{\mathcal{L}_{2}+x_{2} p_{2}}{-p_{2}} \\
\wedge \quad \mathcal{L}_{1}>p_{1}, \mathcal{L}_{2}>-p_{2} x_{2}\end{array}$ \\
\hline coop. subm.2: & $(0,1)$ & 0 & $U_{1}^{1}=0$ & $U_{2}^{2} \leq 0$ & $\begin{array}{l}\frac{p_{1}}{\mathcal{L}_{1}-x_{1} p_{1}}=\frac{B_{1}}{B_{2}} \leq \frac{\mathcal{L}_{2}+p_{2}}{-x_{1} p_{2}} \\
\wedge \mathcal{L}_{1}>p_{1} x_{1}, \mathcal{L}_{2}>-p_{2}\end{array}$ \\
\hline conflict subm.1: & $(0,1)$ & 1 & $U_{1}^{1}=0$ & $U_{2}^{2} \geq 0$ & $\begin{aligned} & \frac{B_{1}}{B_{2}} \geq \frac{\mathcal{L}_{2}}{-x_{1} p_{2}} \\
& \wedge \quad \mathcal{L}_{1}=p_{1} x_{1}\end{aligned}$ \\
\hline conflict subm.2: & 1 & $(0,1)$ & $U_{1}^{1} \geq 0$ & $U_{2}^{2}=0$ & $\begin{aligned} & \frac{B_{1}}{B_{2}} \leq \frac{x_{2} p_{1}}{\mathcal{L}_{1}} \\
& \wedge \quad \mathcal{L}_{2}=-p_{2} x_{2}\end{aligned}$ \\
\hline polarization 1: & 0 & 1 & $U_{1}^{1} \leq 0$ & $U_{2}^{2} \geq 0$ & $\begin{aligned} & \frac{B_{1}}{B_{2}} \geq \frac{\mathcal{L}_{2}}{-p_{2}} \\
\wedge \quad & \mathcal{L}_{1} \geq p_{1}\end{aligned}$ \\
\hline polarization 2 : & 1 & 0 & $U_{1}^{1} \geq 0$ & $U_{2}^{2} \leq 0$ & $\begin{aligned} & \frac{B_{1}}{B_{2}} \leq \frac{p_{1}}{\mathcal{L}_{1}} \\
& \wedge \quad \mathcal{L}_{2} \geq-p_{2}\end{aligned}$ \\
\hline
\end{tabular}

Table A.1: Equilibrium strategies and conditions for their existence.

(FOC as defined in (11) to (13); coop. = cooperation, subm. = submission.

$$
U_{i}^{i}:=\partial U_{i} / \partial y_{i}, i=1,2 \text {.) }
$$




\section{A.3 Split lobbying: the calculation of the example}

This example was calculated using Maple V Release $5 .^{27}$ The relevant equations

$$
\begin{aligned}
a y_{1}^{2}+y_{2}^{2}+2 a y_{1} y_{2}-(1+a) y_{2} & =0 \\
a y_{1}^{2}+y_{2}^{2}+2 y_{1} y_{2}-(1+a) y_{1} & =0
\end{aligned}
$$

imply the following feasible solutions:

$$
\begin{aligned}
& y_{1}^{N}(a)=\frac{1}{2} \cdot \frac{(4 \sqrt{a}-4)(1+a)}{(4 a-4)\left(\frac{(4 \sqrt{a}-4) a}{4 a-4}-\frac{(4 \sqrt{a}-4)}{4 a-4}+1\right)} \\
& y_{2}^{N}(a)=\frac{1}{2} \cdot \frac{(4 \sqrt{a}-4)(1+a)}{4 a-4} .
\end{aligned}
$$

These solutions for $y_{1}^{N}$ and $y_{2}^{N}$ are presented in figure 1 in the text. The following solutions are infeasible:

- $y_{1}=y_{2}=0$ : Since we use the Tullock contest-success function $p=y_{1} /\left(y_{1}+y_{2}\right)$, neither $p$, nor $p_{1}$, nor $p_{2}$ are defined in our example if $y_{1}=y_{2}=0$.

- $y_{1}=\frac{1+a}{a-1} ; \quad y_{2}=-\frac{1+a}{a-1}$ : Every positive $y_{1}$ is matched by a negative $y_{2}$ and vice versa. This violates the non-negativity constraints for $y_{1}$ and $y_{2}$ (Assumption 2).

\section{A.4 Endogenizing the sum of lobbying efforts}

In the text we have assumed that the total time endowment for lobbying is exogenously given, $x_{i}+y_{i}=1$. In this extension we show that this assumption can easily be given up without changing the qualitative results.

Let us assume that the agents split their total endowment of time into jointlobbying efforts $x_{i}$, antagonistic-lobbying efforts $y_{i}$ and productive efforts $e_{i}$, where $x_{i}+y_{i}+e_{i}=1, i=1,2$. We assume that $e_{i} \in\left[e_{i}^{m i n}, 1\right]$, where $e_{i}^{\text {min }}>0$ are the minimal amounts of productive efforts the bureaucrats must exert unless they will be fired. This implies the assumption that the bureaucrats must produce at least a minimal amount of output. Although the sponsor cannot exactly observe the agents' output, he recognizes if the public-good supply falls below some very low threshold. Maybe, it is the media which make him recognize this far-reaching failure of the bureaucrats.

The explicit introduction of productive efforts refers to the following production technology. 
Assumption 1* (production technology, joint lobbying): The total departmental budget consists of the monetary expenditures for a particular public good plus additional money which results from joint lobbying:

$$
B=G\left(e_{1}, e_{2}, 2 \bar{K}\right)+L\left(x_{1}, x_{2}\right)
$$

The functions $G$ and $L$ are twice continuously differentiable. They exhibit positive but non-increasing marginal products, $B_{1}>0, B_{2}>0, B_{11} \leq 0$ and $B_{22} \leq 0$; $L_{1}>0, L_{2}>0, L_{11} \leq 0$ and $L_{22} \leq 0$. The cross derivatives $B_{12}$ and $L_{12}$ may be zero, positive, or negative. $L(0,0)=0, L\left(1-e_{1}^{\min }, 1-e_{2}^{\min }\right)=\bar{L}$.

Assumption $1^{*}$ replaces assumption 1. G are the minimal expenditures which are necessary to produce a particular public good, given the bureaucratic production efforts $e_{1}, e_{2}$ and the capital investments $2 \bar{K}$. The joint-lobbying efforts aim at increasing the total departmental budget above the purely productive expenditures $G(\cdot)$. Only the bureaucrats know the precise technology which drives $G(\cdot)$, only they can tell apart $G$ and $L$. (The only exception is the above-mentioned minimal level of public-good supply.)

Once again, the total budget finances the bureaucratic incomes plus the capital investments plus, possibly, pure waste,

$$
B=G\left(e_{1}, e_{2}, 2 \bar{K}\right)+L\left(x_{1}, x_{2}\right) \geq I+J+2 \bar{K} .
$$

To understand this inequality properly, the reader may consider that a fully informed sponsor would appropriate a budget with $L=0$, that is,

$$
B=G\left(e_{1}, e_{2}, 2 \bar{K}\right)=I+J+2 \bar{K}
$$

where $I$ and $J$ were considered as compensations for the productive efforts $e_{1}$ and $e_{2}$. The sponsor's lack of information enables the bureaucrats to induce $L>0$, which partly may increase their incomes and partly may be used for pure waste.

Assumption 2 (antagonistic lobbying) and Assumption 3 (income schedules) remain unchanged. It is impossible to condition incomes on the amount of productive efforts because these are private information of the bureaucrats. The bureaucrats' objective functions also remain unchanged. In these objective functions there is still no need to explicitly consider the agents' disutilities from effort since the sum of all efforts is exogenous and normalized to unity and we do not assume that different kinds of efforts cause different disutilities.

Once again we assume that the agents first decide on the feasibility of the project. If the project if found feasible, each agent maximizes his utility with respect 
to $e_{i}$ and $y_{i}$ considering the special constraints for this two instrument variables, and taking as given the efforts of the other bureaucrat. Let us present the optimization approach of agent 1 , the extension to agent 2 is straightforward.

$$
\begin{array}{rlr} 
& \max _{e_{1}, y_{1}} \theta_{1} p B+\left(1-\theta_{1}\right) I \\
& \text { subject to } \\
e_{1} \in\left[e_{1}^{\text {min }}, 1\right], & \left(\mu_{11}, \mu_{12}\right), \\
y_{1} \in\left[0,1-e_{1}\right], & \left(\mu_{13}, \mu_{14}\right),
\end{array}
$$

where $\mu_{11}$ to $\mu_{14}$ are the Lagrangean parameters associated with the constraints. Completely new are the results which refer to the optimal choice of productive-effort levels $e_{i}$. The first-order conditions are different according to the type of income schedule. For agent 1, we obtain

$$
\begin{aligned}
I=\bar{I}: \quad & p\left[G_{1}-L_{1}\right]\left\{\theta_{1}\right\} \gtreqless 0, \\
I=I(B): \quad & {\left[G_{1}-L_{1}\right]\left\{p \theta_{1}+\left(1-\theta_{1}\right) I^{\prime}\right\} \gtreqless 0, } \\
I=I(p B): \quad & p\left[G_{1}-L_{1}\right]\left\{\theta_{1}+(1-\theta) I^{\prime}\right\} \gtreqless 0 . \\
\forall I: \quad & \mu_{11}\left(1-e_{1}\right)=0, \quad \mu_{12} e_{1}=0 \quad \mu_{11}, \mu_{12} \geq 0 .
\end{aligned}
$$

Analogous conditions hold for agent 2. Since in (A.3) to (A.5) the terms in braces are always strictly positive, we have the following interesting result. Of course, the quantities of productive effort will differ according to the income schedule the bureaucrats face. However, the qualitative results are independent of the income schedule. There will be no lobbying at all if the bureaucrats can most easily increase their budget by increasing the amount of the public good $\left(G_{1}>L_{1} \Rightarrow e_{1}=1\right)$. On the other hand, the bureaucrats will only exert minimal effort if lobbying is the easier way to maximize the individual budgets $\left(G_{1}<L_{1} \Rightarrow e_{1}=e_{1}^{\text {min }}\right)$.

When it comes to the differentiation with respect to the antagonistic-lobbying efforts $y_{i}$, we recognize that the results are qualitatively the same as in sections 3 and 4 . For agent 1 , we obtain the following first-order conditions:

$$
I=\bar{I}: \quad\left[p_{1} B-p L_{1}\right]\left\{\theta_{1}\right\} \gtreqless 0,
$$




$$
\begin{aligned}
& I=I(B): {\left[p_{1} B-p L_{1}\right] \theta_{1}-\left(1-\theta_{1}\right) I^{\prime} L_{1} \gtreqless 0, } \\
& I=I(p B): \quad\left[p_{1} B-p L_{1}\right]\left\{\theta_{1}+\left(1-\theta_{1}\right) I^{\prime}\right\} \gtreqless 0 . \\
& \forall I: \quad \mu_{13}\left(1-y_{1}\right)=0, \quad \mu_{14} y_{1}=0, \quad \mu_{13}, \mu_{14} \geq 0 .
\end{aligned}
$$

These conditions imply the same qualitative results as (11) to (13) in the text. The only difference consists in $L_{1}$ replacing $B_{1}$. The explicit consideration of productive efforts $e_{i}$ changes the boundaries of the antagonistic-effort levels, but otherwise we face the same type of corner solutions. Therefore, all qualitative results of the text hold as well if the total time endowment for lobbying is endogenized.

\section{Notes}

${ }^{22}$ This proof follows Bös and Kolmar (2000).

${ }^{23}$ For the hypothetical Nash equilibrium of stage 1 a similar proof holds.

${ }^{24}$ For the hypothetical Nash equilibrium of stage 1 a similar proof holds.

${ }^{25}$ Note that Assumption 2 excludes a sharing rule with equal shares regardless of the antagonistic efforts, that is, $p\left(y_{1}, y_{2}\right)=1 / 2 \forall y_{1}, y_{2}$. Such a sharing rule would not guarantee an equilibrium with $B=x_{1}+x_{2}$ for all possible realizations of $p B$ and $(1-p) B$ given $B=\bar{I}+\bar{J}+2 \bar{K}$.

${ }^{26}$ Compare Table A.1 in Bös and Kolmar (2000).

${ }^{27}$ I gratefully acknowledge the help of Torsten Krause. 


\section{CESifo Working Paper Series}

(for full list see www.cesifo.de)

739 Robert J. Gary-Bobo and Sophie Larribeau, A Structural Econometric Model of Price Discrimination in the Mortgage Lending Industry, June 2002

740 Laurent Linnemer, When Backward Integration by a Dominant Firm Improves Welfare, June 2002

741 Gebhard Kirchgässner and Friedrich Schneider, On the Political Economy of Environmental Policy, June 2002

742 Christian Keuschnigg and Soren Bo Nielsen, Start-ups, Venture Capitalits, and the Capital Gains Tax, June 2002

743 Robert Fenge, Silke Uebelmesser, and Martin Werding, Second-best Properties of Implicit Social Security Taxes: Theory and Evidence, June 2002

744 Wendell Fleming and Jerome Stein, Stochastic Optimal Control, International Finance and Debt, June 2002

745 Gene M. Grossman, The Distribution of Talent and the Pattern and Consequences of International Trade, June 2002

746 Oleksiy Ivaschenko, Growth and Inequality: Evidence from Transitional Economies, June 2002

747 Burkhard Heer, Should Unemployment Benefits be Related to Previous Earnings?, July 2002

748 Bas van Aarle, Giovanni Di Bartolomeo, Jacob Engwerda, and Joseph Plasmans, Staying Together or Breaking Apart: Policy-makers' Endogenous Coalitions Formation in the European Economic and Monetary Union, July 2002

749 Hans Gersbach, Democratic Mechanisms: Double Majority Rules and Flexible Agenda Costs, July 2002

750 Bruno S. Frey and Stephan Meier, Pro-Social Behavior, Reciprocity or Both?, July 2002

751 Jonas Agell and Helge Bennmarker, Wage Policy and Endogenous Wage Rigidity: A Representative View From the Inside, July 2002

752 Edward Castronova, On Virtual Economies, July 2002

753 Rebecca M. Blank, U.S. Welfare Reform: What's Relevant for Europe?, July 2002

754 Ruslan Lukach and Joseph Plasmans, Measuring Knowledge Spillovers Using Patent Citations: Evidence from the Belgian Firm's Data, July 2002 
755 Aaron Tornell and Frank Westermann, Boom-Bust Cycles in Middle Income Countries: Facts and Explanation, July 2002

756 Jan K. Brueckner, Internalization of Airport Congestion: A Network Analysis, July 2002

757 Lawrence M. Kahn, The Impact of Wage-Setting Institutions on the Incidence of Public Employment in the OECD: 1960-98, July 2002

758 Sijbren Cnossen, Tax Policy in the European Union, August 2002

759 Chandima Mendis, External Shocks and Banking Crises in Developing Countries: Does the Exchange Rate Regime Matter?, August 2002

760 Bruno S. Frey and Lars P. Feld, Deterrence and Morale in Taxation: An Empirical Analysis, August 2002

761 Lars Calmfors and Åsa Johansson, Nominal Wage Flexibility, Wage Indexation and Monetary Union, August 2002

762 Alexander R. W. Robson and Stergios Skaperdas, Costly Enforcement of Property Rights and the Coase Theorem, August 2002

763 Horst Raff, Preferential Trade Agreements and Tax Competition for Foreign Direct Investment, August 2002

764 Alex Cukierman and V. Anton Muscatelli, Do Central Banks have Precautionary Demands for Expansions and for Price Stability? - Theory and Evidence, August 2002

765 Giovanni Peri, Knowledge Flows and Knowledge Externalities, August 2002

766 Daniel Friedman and Nirvikar Singh, Equilibrium Vengeance, August 2002

767 Sam Bucovetsky and Michael Smart, The Efficiency Consequences of Local Revenue Equalization: Tax Competition and Tax Distortions, August 2002

768 Tapio Palokangas, International Labour Market Regulation and Economic Growth with Creative Destruction, August 2002

769 Rudi Dornbusch, The New International Architecture, September 2002

770 Hans-Werner Sinn, Weber's Law and the Biological Evolution of Risk Preferences: The Selective Dominance of the Logarithmic Utility Function, September 2002

771 Thomas Mayer, The Macroeconomic Loss Function: A Critical Note, September 2002

772 Seppo Honkapohja and Kaushik Mitra, Learning Stability in Economies with Heterogenous Agents, September 2002

773 David Laidler, Inflation Targets Versus International Monetary Integration - A Canadian Perspective, September 2002 
774 Morten I. Lau, Panu Poutvaara, and Andreas Wagener, The Dynamic Cost of the Draft, September 2002

775 Steven Brakman, Harry Garretsen, and Charles van Marrewijk, Locational Competition and Agglomeration: The Role of Government Spending, September 2002

776 Anke S. Kessler and Christoph Lülfesmann, The Theory of Human Capital Revisited: On the Interaction of General and Specific Investments, September 2002

777 Kjell Erik Lommerud, Frode Meland and Lars Sørgard, Unionized Oligopoly, Trade Liberalization and Location Choice, September 2002

778 Antonio Merlo and François Ortalo-Magné, Bargaining over Residential Real Estate: Evidence from England, September 2002

$779 \mathrm{Yu}-\mathrm{Fu}$ Chen and Michael Funke, Exchange Rate Uncertainty and Labour Market Adjustment under Fixed and Flexible Exchange Rates, September 2002

780 Michael S. Michael, International Migration, Income Taxes and Transfers: A Welfare Analysis, September 2002

781 Clemens Fuest and Alfons Weichenrieder, Tax Competition and Profit Shifting: On the Relationship between Personal and Corporate Tax Rates, October 2002

782 Jan Bouckaert and Hans Degryse, Softening Competition by Enhancing Entry: An Example from the Banking Industry, October 2002

783 Johann K. Brunner and Susanne Pech, Adverse Selection in the Annuity Market with Sequential and Simultaneous Insurance Demand, October 2002

784 Gregory D. Hess and Eduard Pelz, The Economic Welfare Cost of Conflict: An Empirical Assessment, October 2002

785 Jan Erik Askildsen, Uwe Jirjahn, and Stephen C. Smith, Works Councils and Environmental Investment: Theory and Evidence from German Panel Data, October 2002

786 Geir H. Bjønnes, Dagfinn Rime, and Haakon O. Aa. Solheim, Volume and Volatility in the FX-Market: Does it matter who you are?, October 2002

787 John Evans and John Fingleton, Entry Regulation and the Influence of an Incumbent Special Interest Group, October 2002

788 Wolfgang Ochel, International Comparisons and Transfer of Labour Market Institutions, October 2002

789 B. Gabriela Mundaca, Moral Hazard Effects of Bailing out under Asymmetric Information, October 2002

790 Gene M. Grossman and Edwin L.-C. Lai, International Protection of Intellectual Property, October 2002 
791 John Hassler, José V. Rodriguez Mora, Kjetil Storesletten, and Fabrizio Zilibotti, A Positive Theory of Geographic Mobility and Social Insurance, October 2002

792 Paul De Grauwe and Marianna Grimaldi, The Exchange Rate in a Model with Heterogeneous Agents and Transactions Costs, October 2002

793 Guido Friebel and Mariassunta Giannetti, Fighting for Talent: Risk-shifting, Corporate Volatility, and Organizational Change, October 2002

794 Jan Erik Askildsen, Badi H. Baltagi, and Tor Helge Holmås, Will Increased Wages Reduce Shortage of Nurses? A Panel Data Analysis of Nurses' Labour Supply, October 2002

795 Marko Köthenbürger and Panu Poutvaara, Social Security Reform and Intergenerational Trade: Is there Scope for a Pareto-Improvement?, October 2002

796 Paul De Grauwe and Laura Rinaldi, A Model of the Card Payment System and the Interchange Fee, October 2002

797 Volker Böhm and Tomoo Kikuchi, Dynamics of Endogenous Business Cycles and Exchange Rate Volatility, October 2002

798 Mariam Camarero, Javier Ordóñez, and Cecilio Tamarit, The Euro-Dollar Exchange Rate: Is it Fundamental?, October 2002

799 Misa Tanaka, How Do Bank Capital and Capital Adequacy Regulation Affect the Monetary Transmission Mechanism?, October 2002

800 Jörg Baten and Andrea Wagner, Autarchy, Market Disintegration, and Health: The Mortality and Nutritional Crisis in Nazi Germany, 1933-1937, October 2002

801 Saku Aura, Uncommitted Couples: Some Efficiency and Policy Implications of Marital Bargaining, October 2002

802 Wolfram F. Richter, Delaying Integration of Immigrant Labor for the Purpose of Taxation, October 2002

803 Gil S. Epstein and Shmuel Nitzan, The Politics of Randomness, October 2002

804 John Hassler and José V. Rodriguez Mora, Should UI Benefits Really Fall over Time?, October 2002

805 Friedrich Breyer and Stefan Felder, The Dead-anyway Effect Revis(it)ed, October 2002

806 Assar Lindbeck and Solveig Wikström, E-exchange and the Boundary between Households and Organizations, November 2002

807 Dieter Bös, Contests Among Bureaucrats, November 2002 